\title{
SYNTHESIS AND BIOLOGICAL EVALUATION OF CIS-COMBRETASTATIN ANALOGS AND THEIR NOVEL 1,2,3-TRIAZOLE DERIVATIVES
}

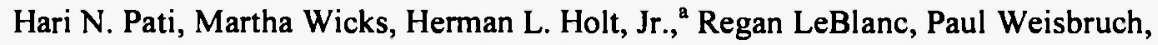 \\ Lori Forrest, Moses Lee* \\ Moses.Lee@furman.edu \\ Department of Chemistry, Furman University, Greenville, SC 29613 \\ aDepartment of Chemistry, University of North Carolina, Asheville, NC 28804
}

\begin{abstract}
Three cis-combretastatin analogs $(8-10)$ and three novel 1,2,3-triazole derivatives $(5-7)$ have been synthesized. The cis-combretastatins were prepared from selective hydrogenation of the corresponding alkyne. Reaction of the alkyne intermediates with benzyl azide via the [3+2] dipolar cycloaddition provided the 1,2,3-triazoles compounds. Removal of the benzyl group by catalytic hydrogenation afforded the desired triazoles $5-7$ in good yields. The cytotoxicity of the target compounds against the growth of murine B16 melanoma cells was determined using a MTT-based assay. The results demonstrated the triazoles to have cytotoxicity comparable to the cis-combretastatins, with the $\mathrm{IC}_{50}$ values for compounds 7 and 10 as $56 \mu \mathrm{M}$ and $55 \mu \mathrm{M}$, respectively.
\end{abstract}

\section{Introduction}

Combretastatins, isolated from the African willow tree Combretum caffrum Kuntze (Combretaceae), are known to inhibit the growth of cancer cells (murine P388 lymphocytic leukemia). The most potent compound of this class of natural products is combretastatin A-4 (CA-4, 1), which strongly inhibits the polymerization of tubulin by binding to the colchicine site. 'Major limitations on the clinical utility of CA-4 are its poor solubility in biological media and poor bioavailability, which significantly impair its in-vivo activity. In addition, the combretastatins contain a core cis-stilbene nucleus, which upon heating tends to isomerize to the trans-double bond configuration. While it was found that trans-combretastatins have cytotoxic properties, ${ }^{2}$ the interconversion from cis- to trans-combretastatins is not ideal for drug development. As a result, there is significant interest in the design of combretastatin analogs that have more beneficial pharmacological properties. Compound 2, a synthetic water soluble phosphate prodrug of CA-4 is currently undergoing clinical trials. ${ }^{3}$ In addition, an amino analog of CA-4 (3) and its amino acid derivative 4, have also been found to have more favorable water solubility and in-vivo anticancer activity, with the latter also undergoing clinical evaluation. ${ }^{4}$ In addition, analogs of combretastatins, where a heterocycle serves as a bridge between the two aromatic ring systems, have been prepared. These corresponding molecules include imidizoles, oxazoles, pyrazoles, thiazoles, 1,2,4-triazoles, and tetrazoles. ${ }^{5}$ A number of these heterocyclic analogs have been found to have potent anticancer activity.
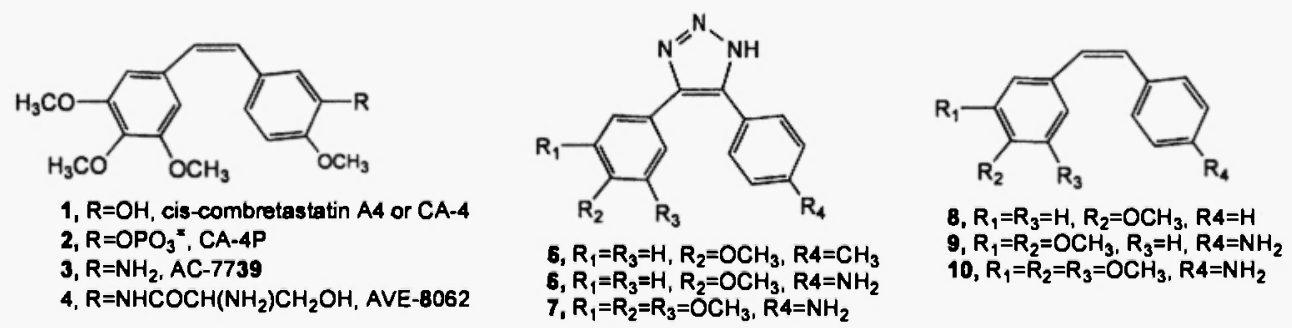

Figure 1. Structures of combretastatin A4 (1), CA-4P (2), amino-combretastatin AC-7739 (3), the amino acid derivative 4 , and the cis-combretastatin analogs $(8-10)$ and their 1,2,3-triazole derivatives $(5-7)$. 
Our research is focused on a novel class of heterocyclic combretastatin analogs, 4,5-diaryl-1,2,3-triazoles, which has not been investigated heretofore. These triazoles will maintain the rigidity about the $\pi$-bond as well as the cis-configuration of the aromatic rings. This conformation will ensure that the triazoles will mimic the combretastatins and fit into the colchicine binding site in tubulin. Moreover, like imidazoles, 1,2,3-triazoles are polar and slightly basic making them readily protonated as $\mathrm{HCl}$ salts. ${ }^{6} 1,2,3$-Triazoles are also useful as medicinal agents, including anticancer drugs, ${ }^{7}$ suggesting that they are stable in biological environments. In this paper, we report a highly convergent method for the preparation of the cis-combretastatin analogs and their 1,2,3-triazole derivatives, as well as a brief discussion on the cytotoxic properties of the target compounds 5 - 10 .

\section{Results and Discussion}

The synthetic strategy for the generation of the target cis-combretastatins (8 - 10) and their 1,2,3-triazoles derivatives $(5$ 7) is shown in Scheme 1. The key feature of this strategy is that both aryl groups of the final products are derived from appropriate benzaldehyde synthons. This highly versatile synthetic approach allows for the possibility to create a wide range of molecules, based on the availability of substituted benzaldehydes. The substituents on the aromatic rings will be important as we examine the functionality of the final products and how the substituents play a role in affecting biological activity. Reaction of substituted benzyl bromides with triphenylphospine in a benzene solution afforded the corresponding phosphonium bromides $(11$ - 13). Treatment of the phosphonium bromides with sodium hydride produced the corresponding Wittig reagents, which were reacted with substituted benzaldehydes (14 - 16) to generate the stilbenes (17 21 ) in good yields. Based on the coupling constants for the vinylenic protons of $16 \mathrm{~Hz}$, and the chemical shift<smiles>[R]c1cc(C[PbH2]Br)cc([R])c1[R]</smiles>

$11, R_{1}=R_{2}=R_{3}=H$ 12, $R_{1}=R_{3}=H_{1}, R_{2}=\mathrm{CH}_{3}$

$13, R_{1}=R_{3}=H_{1} R_{2}=\mathrm{NO}_{2}$

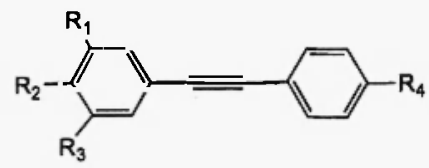

27, $R_{1}=\mathbf{R}_{3}=\mathrm{H}_{1}, \mathbf{R}_{\mathbf{2}}=\mathrm{OCH}_{3}, \mathbf{R} 4=\mathrm{H}(50 \%)$

28, $R_{1}=R_{3}=H_{1}, R_{2}=O^{2} C_{3}, R 4=C_{3}(92 \%)$

29, $R_{1}=R_{3}-H_{1} R_{2}=\mathrm{OCH}_{3}, R_{4}=\mathrm{NO}_{2}(95 \%)$

30, $R_{1}=R_{2}=\mathrm{OCH}_{3}, \mathbf{R} 4=\mathrm{NO}_{2}(75 \%)$

31, $R_{1}=R_{2}=R_{3}=\mathrm{OCH}_{3}, \mathbf{R} 4=\mathrm{NO}_{2}(95 \%)$

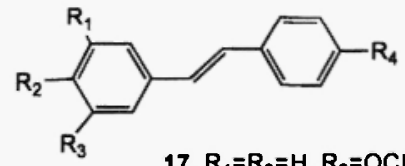

17, $R_{1}=R_{3}=H, R_{2}=\mathrm{OCH}_{3}, \mathbf{R} 4=\mathrm{H}(85 \%)$

14, $\mathrm{R}_{4}=\mathrm{R}_{6}=\mathrm{H}, \mathrm{R}_{5}=\mathrm{OCH}_{3}$

15, $R_{4}=R_{5}=\mathrm{OCH}_{3}, R_{8}=\mathrm{H}$

16, $R_{4}=R_{5}=R_{6}=\mathrm{OCH}_{3}$

$\mathrm{H}_{2}$,

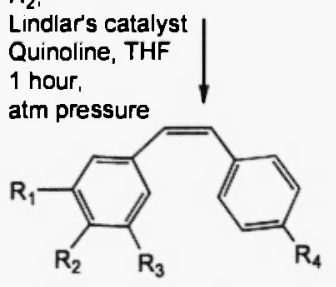

8, $\mathbf{R}_{\mathbf{1}}=\mathbf{R}_{3}=\mathrm{H}_{1} \mathbf{R}_{2}=\mathrm{OCH}_{3}, \mathbf{R} 4=\mathrm{H}(\mathbf{9 2} \%)$ 9, $R_{1}=R_{2}=\mathrm{OCH}_{3}, R_{3}=\mathrm{H}_{1}, R 4=\mathrm{NH}_{2}(98 \%)$ 10, $R_{1}=R_{2}=R_{3}=O_{C H}, R 4=\mathrm{NH}_{2}(88 \%)$

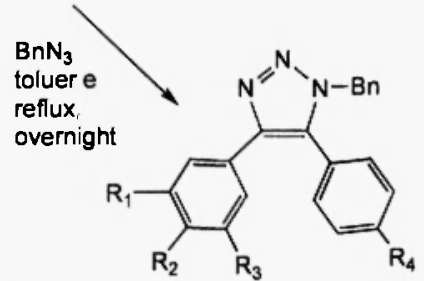

32, $\mathbf{R}_{1}=\mathbf{R}_{3}=\mathrm{H}_{1} \mathbf{R}_{2}=\mathrm{OCH}_{3}, \mathbf{R} 4=\mathrm{CH}_{3}(22 \%)$

33, $R_{1}=R_{3}=H_{1}, R_{2}=\mathrm{OCH}_{3}, R 4=\mathrm{NO}_{2}(42 \%)$

34, $R_{1}=R_{2}=R_{3}=\mathrm{OCH}_{3}, \mathrm{R} 4=\mathrm{NO}_{2}(61 \%)$

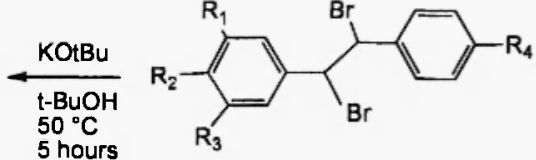

22, $\mathbf{R}_{1}=\mathbf{R}_{3}=\mathrm{H}, \mathbf{R}_{2}=\mathrm{OCH}_{3}, \mathbf{R} 4=\mathrm{H}(\mathbf{9 6 \%})$

23, $\mathbf{R}_{1}=\mathbf{R}_{3}=\mathrm{H}, \mathbf{R}_{2}=\mathrm{OCH}_{3}, \mathbf{R} 4=\mathrm{CH}_{3}(95 \%)$

24, $R_{1}=R_{3}=\mathrm{H}, R_{2}=\mathrm{OCH}_{3}, \mathbf{R} 4=\mathrm{NO}_{2}(92 \%)$

25, $R_{1}=R_{2}=\mathrm{OCH}_{3}, \mathbf{R 4}=\mathrm{NO}_{2}(90 \%)$

26, $R_{1}=R_{2}=R_{3}=\mathrm{OCH}_{3}, R_{4}=\mathrm{NO}_{2}(98 \%)$

Scheme 1. Synthesis of 1,2,3-triazole derivatives $5-7$ and combretastation analogs $8-10$. 
being greater than $6.9 \mathrm{ppm}$, the trans configuration of the double bond was ascertained. Bromination of the stilbenes, followed by didehydrobromination, generated the alkynes (27 - 31) in good yields. Following published procedures, ${ }^{8}$ reduction of the alkynes using Lindlar's catalyst produced the cis-combretastatin analogs 8 - 10 in very high yields. The cis configuration of the double bond in these compounds was confirmed by NMR analysis, in which the coupling constants for the vinylenic protons were around $12 \mathrm{~Hz}$ and the chemical shifts were less than $6.6 \mathrm{ppm}$. Alternatively, the alkynes were reacted under thermal conditions with benzyl azides to form the corresponding 1,2,3-triazoles (32 - 34) in modest yields. Removal of the benzyl group by catalytic hydrogenation afforded the desired triazole derivatives $5-7$. The structures of the compounds in this study were confirmed by NMR, IR, mass spectrometry, and accurate mass measurements for the target compounds 5 - 10.

With the target compounds in hand, their ability to inhibit the growth of murine B16 melanoma cells in culture was determined. The cells were incubated continuously for 72 hours, and the cytotoxicity was measured using a colorimetricbased MTT assay. ${ }^{9}$ The concentrations needed to inhibit the growth of the cancer cells by $50 \%$ for the target compounds are given in Figure 2. Several observations can be made from the results. First, the triazole derivatives show comparable cytotoxicity to the combretastatin analogs. For example, triazole $\mathbf{7}$ and combretastatin 10 have almost identical $\mathrm{IC}_{50}$ values. Second, the results also indicate that having a 3,4,5-trimethoxy substitution pattern on the A-ring is beneficial for cytotoxic potency. This observation is reasonable because the colchicine binding site in tubulin has a preference for a trimethoxy substituted phenyl moiety. ${ }^{10}$ Even though the potency of the triazole 7 is moderate, the triazole nucleus offers favorable solubility in aqueous media, while maintaining the geometry necessary to fit into the colchicines binding site in tubulin. We believe that it represents an alternate class of compounds to the combretastatins worthy of further investigation. Moreover, the availability of substituted benzaldehydes provides an opportunity for the generation of a wide range of triazoles in combinatorial chemistry studies.

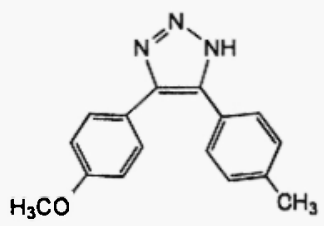

5, $\left(1 \mathrm{C}_{50}=>100 \mu \mathrm{M}\right)$

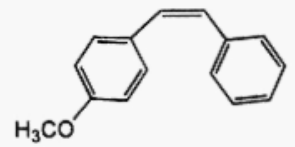

$B_{i}\left(I C_{50}=>100 \mu M\right)$

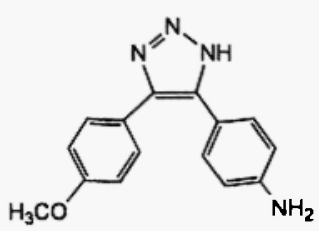

6. $\left(\mathrm{IC}_{50}=>100 \mu \mathrm{M}\right)$

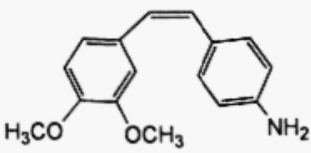

9. $\left(I C_{50}=53 \mu M\right)$

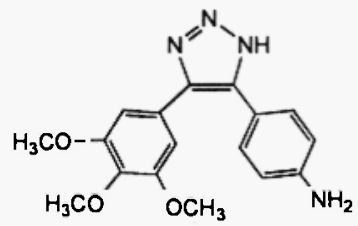

$7\left(\mathrm{CC}_{50}=56 \mu \mathrm{M}\right)$

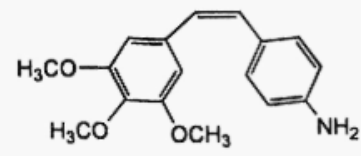

10, $\left(1 \mathrm{C}_{50}=55 \mu \mathrm{M}\right)$

Figure 2. Structures of the target compounds $5-7$ and their $\mathrm{IC}_{50}$ values against the growth of $\mathrm{B} 16$ murine melanoma cells. The compounds were dissolved in DMSO and diluted with DMEM media, with the eventual concentrations of $0.1 \%$ of DMSO. This percentage of DMSO has no effects on the growth of B16 cells. 
Acknowledgements : The authors acknowledge support from the NSF-REU, NIH (RR 16461-10) from the BRIN Program, and Furman University.

\section{References}

1. (a) Pettit, G.R., Singh, S.B., Boyd, M.R., Hamel, E., Pettit, R.K., Schmidt, J.M., Hogan, F. : J. Med. Chem., 38, 1666 (1995). (b) Hamel, E. : Med. Res. Rev., 16, 207 (1996).

2. Pati, H., Taherbhai, Z., Forrest, L., Wicks, M., Bailey, S., Staples, A., Stewart, M., Pennington, W., Harris, J., Lee, M. : Letters in Drug Design and Discovery, 1, 275 (2004).

3. (a) Hadimani, M.B., Hua, J., Jonklaas,k M.D., Kessler, R.J., Sheng, Y., Olivares, A., Tanpure, R.P., Weiser, A., Zhang, J., Edvardsen, K., Kane, R.R., Pinney, K.G. : Bioorg. Med. Chem. Lett. 13, 1505 (2003). (b) Bedford, S.B., Quarterman, C.P., Rathbone, D.L., Slack, J.A., Griffin, R.J., Stevens, M.F.G. : Bioorg. Med. Chem. Lett., 6, 157 (1996).

4. Ohsumi, K., Nakagawa, R., Fukuda, Y., Hatanaka, T., Morinaga, Y., Nihei, Y., Ohishi, K., Suga, Y., Akiyama, Y., Tsuji, T. : J. Med. Chem., 41, 3022 (1998).

5. (a) Wang, L., Woods, K.W., Li, Q., Barr, K.J., McCroskey, R.W., Hannick, S.M., Gherke, L., Credo, R.B., Hui, Y-H., Marsh, K., Warner, R., Lee, J.Y., Zielinski-Mozng, N., Frost, D., Rosenberg, S.H., Sham, H.L. : J. Med. Chem., 45, 1697 (2002). (b) Ohsumi, K., Hatanaka, T., Fujita, K., Nakagawa, R., Fukuda, Y., Nihei, Y., Suga, Y., Morinaga, Y., Akiyama, Y., Tsuji, T. : Bioorg. Med. Chem. Lett., 8, 1505 (1998).

6. Abboud, J-L.M., Foces-Foces, C., Natario, R., Trifonov, R.E., Volovodenko, A.P., Ostrovskii, V.A., Alkorta, I., Elguero, J. : Eur. J. Org. Chem., 3013 (2001).

7. (a) Wehrmann, F. : US Patent January 19, 5,861,406 (1999). (b) Wehrmann, F. : US Patent June $15,5,912,346$ (1999).

8. Mu, F., Hamel, E., Lee, D.J., Pryor, D.E., Cushman, M. : J. Med. Chem., 46, 1670 (2003).

9. Carmichael, J., DeGraff, W.G., Gazdar, A.F., Minna, J.D., Michael, J.B. : Cancer Res., 47, 936 (1987).

10. Graening, T., Schmalz, H-G. : Angew. Chem. Int. Ed., 43, 3230 (2004).

Received on October 10, 2004 